Journal of Engineering and Applied Sciences 7 (2): 215-222, 2012

ISSN: $1816-949 \mathrm{X}$

(C) Medwell Journals, 2012

\title{
Active Technique by Suction to Control the Flow Structure over a Van Model
}

\author{
Harinaldi, Budiarso, Warjito, Engkos A. Kosasih, Rustan Tarakka and Sabar P. Simanungkalit \\ Fluid Engineering Laboratory, Department of Mechanical Engineering, Faculty of Engineering, \\ University of Indonesia Kampus UI Depok, 16242, Indonesia
}

\begin{abstract}
Today research trend in car aerodynamics are carried out from the point of view of the durable development. Some car companies have the objective to develop control solution that enable to reduce the aerodynamic drag of vehicle. It provides the possibility to modify the flow separation to reduce the development of the swirling structures around the vehicle. In this study, a family van was modeled with a modified form of Ahmed's body by changing the orientation of the flow from its original form (modified/reversed Ahmed body). This model was equipped with a suction on the rear side to comprehensively examine the pressure field modifications that occur. The investigation combined computational and experimental work. The computational simulation used k-epsilon Flow Turbulence Model. The reversed Ahmed body used in the investigation had slant angle $(\varphi) 35^{\circ}$ at the front part. In the computational work, meshing type was tetra/hybrid element with hex core type and the grid number was $>1.7$ million in order to ensure detail discretization and more accurate calculation results. The boundary condition was upstream velocity of $11.1 \mathrm{~m} \mathrm{sec}^{-1}$. Mean free stream at far upstream region was assumed in a steady state condition and uniform. The suction velocity was set at $1 \mathrm{~m} \mathrm{sec}^{-1}$. Meanwhile in the experimental work a reversed Ahmed model was tested in a controlled wind tunnel experiments. The main measurement was the aerodynamic drag force measurement at rear of the body of the model using load cell. The results showed that the application of a suction in the rear part of the van model gave the effect of reducing the wake and the vortex formation. Aerodynamic drag reduction close to $24 \%$ for the computational approach and $14.8 \%$ for the experimental approach by introducing a suction had been obtained.
\end{abstract}

Key words: Active flow control, suction, aerodynamic drag reduction, reversed Ahmed body, load cell, Indonesia

\section{INTRODUCTION}

The energy crisis is a complex problem that being faced by many countries in the world. Further, there has been an unbalanced relationship between the increasing demands with oil reserves decrement. At the same time, burning process of fossil fuel generates a negatives effect for the preservation of nature.

Residual gases from fossil fuel burning process cause a greenhouse effect which became one of the causes of global warming. In this context, the gas emissions with greenhouse effect will increase closely of $57 \%$ in 2030 with strong effects on the environment and the climate (International Energy Agency, 2007). One of the biggest users of fossil fuels is automobiles. Concerning the road vehicles, the world park counted in 2002 nearly 590 million units. In this context, the annual $\mathrm{CO}_{2}$ emissions exceed already the 22 billion ton whereas the requirements in transport vehicles for the emergent countries increase. Therefore a new innovation in automobile technology to answer the problem of energy crisis and global warming is required. Modification of automobile technology is one of solution that can be applied to transform and achieve sustainable energy and the preservation of nature. Significant modification progress is still possible by reducing the mass, rolling friction or aerodynamic drag. This modification is intended to achieve fuel efficiency so as to reduce the rate of fuel consumption (Watkins and Gioacchino, 2008; Kassim and Filippone, 2010; Rose, 1981). In the aerodynamic aspect, research has already been started about 20 years ago with the purpose of obtaining an understanding of physical phenomena that can be solutions of drag reduction in vehicles. The research developed today in car aerodynamics is carried out from the point of view of the durable development. Some automobiles companies have the objective to develop control solutions which are able to reduce at least $30 \%$ of the aerodynamic drag of the vehicles without constraints on the design, the comfort, the storage or the safety of the passengers (Kourta and Gillieron, 2009).

Corresponding Author: Harinaldi, Fluid Engineering Laboratory, Department of Mechanical Engineering, Faculty of Engineering, University of Indonesia Kampus UI Depok, 16242, Indonesia 
The flow region which presents the major contribution to the drag force on a car and which poses severe problems to numerical predictions and experimental studies as well is the wake flow behind the car. The location at which the flow separates determines the size of the separation zone and consequently the drag force. To reduce the aerodynamic drag of automotive vehicles by local modification of the flow in a given design and to have a negligible impact on the vehicle geometry, the key issue consists in reducing the transversal wake section, increasing the static pressure distribution on the rear part of the vehicle and reducing the total pressure losses in the near-wake flow (Onorato et al., 1984). Meanwhile, Harinaldi et al. (2011), conducted research in computational active flow control and stated that the application of active control by suction can reduce the aerodynamic drag of modified Ahmed body up to $15.83 \%$. The separated flow is the seat of two contra rotating movements which converge towards two separations focuses (Gillieron and Chometon, 1999). The flow resulting from these two focuses interacts and feeds then the base flow. Part of the flow resulting from the side parts of the geometry separates on the side of the rear window and creates two contra rotating longitudinal swirling structures. At the base, the flow separates at the periphery to generate a torus swirling structure which interacts with the separated flow of the rear window. This complex topology can be modified using passive or active control systems (Bruneau et al., 2010).

A simplified car as the Ahmed body (Ahmed et al., 1984) is a three-dimensional bluff body moving in the vicinity of the ground generating a turbulent flow. Several separations appear along the body from the front to the back. The resulting recirculation zones contribute to a significant part of the drag coefficient (Gillieron and Spohn, 2002). So an objective of the control is to reduce the transverse separation area in the wake. The drag coefficient changes strongly with the angle $\alpha$ between the horizontal line and the rear window (Uruba and Hladik, 2009). For low angles $<12^{\circ}$ or large angles $>30^{\circ}$, the flow separates at the back and is mainly a two-dimensional base flow. Especially, experimental and numerical studies confirm the two-dimensional behaviour of the detached near-wall flow at the base of the square back Ahmed body geometry (Gillieron and Chometon, 1999). On the contrary for angles between these two values of $\alpha$, the flow is highly three-dimensional over the rear window as there are two counter-rotary lateral vortices and an open separation bulb (Gillieron and Chometon, 1999).

In this study, a bluff body is modeled with a modified form of Ahmed's body by changing the orientation of the flow from its original form (modified/reversed Ahmed body) in order to resemble a practical van model. This model is equipped with a suction on the rear side to comprehensively examine the pressure field modifications that occur. The investigation combines computational and experimental work.

\section{MATERIALS AND METHODS}

This study examines the drag reduction that occurs in a bluff body van model adapted from Ahmed model in which the free stream flow in reversed direction to the original model (reversed Ahmed model). The van model was equipped with an active control by an application of suction.

Reversed Ahmed body model was used because it represented a typical form of family van which commonly produced by car manufacturer. The van model was used both in the Computational Methods (CFD) and experimental.

Computational approach: Computational work was conducted to simulate the flow conditions around the models. This was carried out to develop an appropriate prediction tools to assist the determination of influencing parameters to be used in the experimental works. Figure 1 shows the van model used in this investigation. The geometries ratio of van model used in this study to the original Ahmed body model (Ahmed et al., 1984) was 0.25. Therefore, the van model geometry was defined by its length $(1=0.261 \mathrm{~m})$ width $(\mathrm{w}=0.09725 \mathrm{~m})$ and its height $(\mathrm{h}=0.072 \mathrm{~m})$. In this configuration, the front part of body was inclined at an angle $\varphi=35^{\circ}$ with respect to the horizontal.

The 3D computational domain is shown in Fig. 2 which has dimensions of Length $(\mathrm{L})=81$, Width $(\mathrm{W})=21$ and Height $(\mathrm{H})=21(1=$ length of model in x-axis $)$. Meshing type was tetra/hybrid element with hex core type and the grid number was $>1.7$ million in order to ensure detail discretization and more accurate calculation results.

The boundary condition was inlet velocity of $11.1 \mathrm{~m} \mathrm{sec}^{-1}$. Mean free stream at far upstream region was assumed in a steady state condition and uniform. The suction velocity is set $1 \mathrm{~m} \mathrm{sec}^{-1}$. Reynolds number corresponding with the length of the test model was $\operatorname{Re}=1.99 \times 10^{5}$.

Details of computational conditions are shown in Table 1, Fig. 2. The governing equations were solved numerically by finite volume approach using a commercial solver Fluent 6.3. The turbulence model used in the computation was a standard k-epsilon model showed in Eq. 1 and 2: 


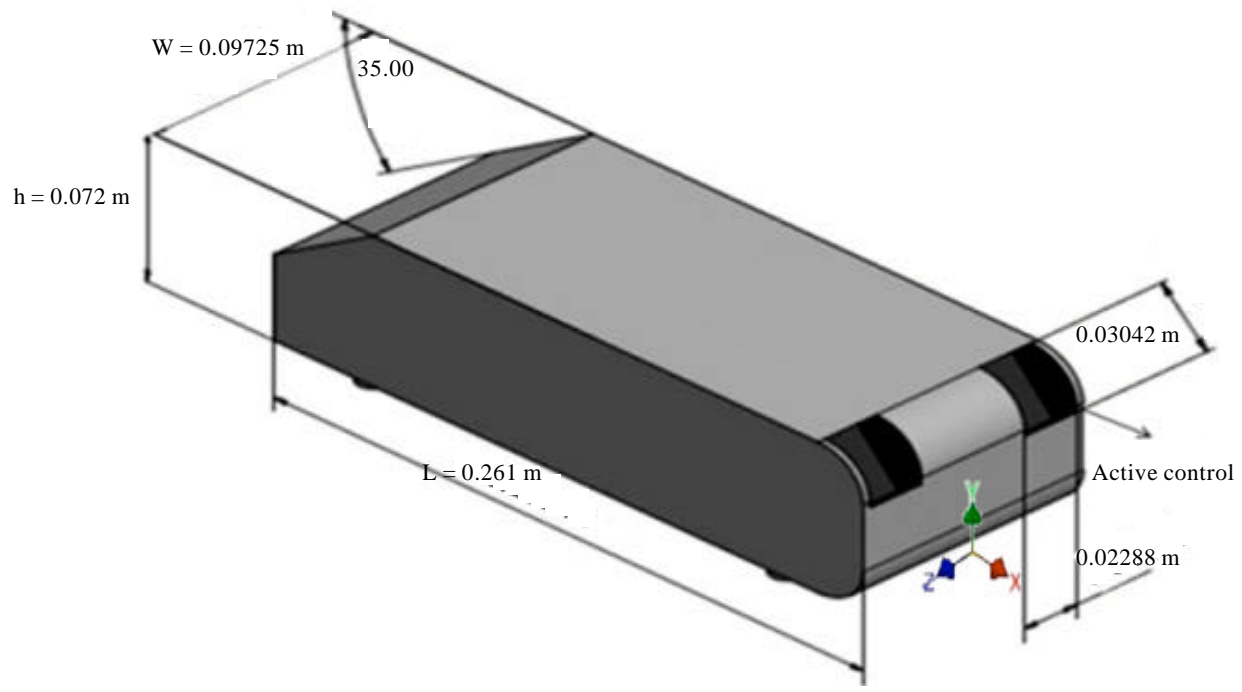

Fig. 1: Van model of the type of a reversed Ahmed body

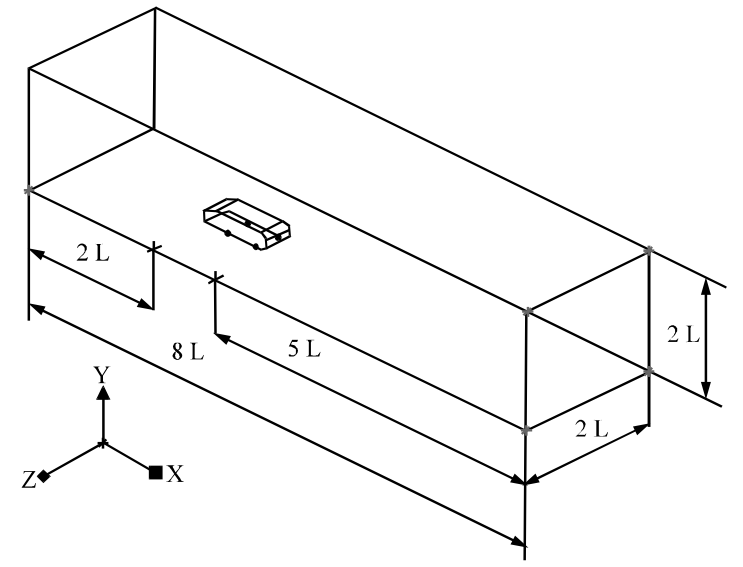

Fig. 2: Computational flow domain

\begin{tabular}{|c|c|c|}
\hline \multicolumn{3}{|c|}{ Computational condition } \\
\hline Model (fluid) & \multicolumn{2}{|c|}{ 3D, steady state (air) } \\
\hline \multirow[t]{2}{*}{ Fluid properties } & Density & $1.225 \mathrm{~kg} \mathrm{~m}^{-3}$ \\
\hline & Viscosity & $0.000017894 \mathrm{~kg} \mathrm{msec}^{-1}$ \\
\hline \multirow{4}{*}{$\begin{array}{l}\text { Boundary condition } \\
\text { without flow control }\end{array}$} & Test model & Wall \\
\hline & Pressure outlet & Pressure outlet \\
\hline & Velocity inlet & Velocity inlet \\
\hline & Wall & Wall \\
\hline \multirow{6}{*}{$\begin{array}{l}\text { Boundary condition } \\
\text { with suction }\end{array}$} & Test model & Wall \\
\hline & Pressure outlet & Pressure outlet \\
\hline & Velocity inlet & Velocity inlet \\
\hline & Wall & Wall \\
\hline & Suction 1 & Velocity inlet \\
\hline & Suction 2 & Velocity inlet \\
\hline Suction velocity & $1 \mathrm{~m} \mathrm{sec}^{-1}$ & \\
\hline Upstream velocity & $11.1 \mathrm{~m} \mathrm{sec}^{-1}$ & \\
\hline
\end{tabular}

$$
\frac{\partial}{\partial \mathrm{t}}(\rho \mathrm{k})+\frac{\partial}{\partial \mathrm{x}_{\mathrm{i}}}\left(\rho \mathrm{ku}_{\mathrm{i}}\right)=\frac{\partial}{\partial \mathrm{x}_{\mathrm{j}}}\left|\left(\mu+\frac{\mu_{\mathrm{t}}}{\sigma_{\mathrm{k}}}\right) \frac{\partial \mathrm{k}}{\partial \mathrm{x}_{\mathrm{j}}}\right|+\mathrm{p}_{\mathrm{k}}+\mathrm{p}_{\mathrm{b}}-\rho_{\epsilon}-\mathrm{Y}_{\mathrm{M}}+\mathrm{S}_{\mathrm{k}}
$$

$$
\begin{aligned}
\frac{\partial}{\partial \mathrm{t}}(\rho \in)+\frac{\partial}{\partial \mathrm{x}_{\mathrm{i}}}\left(\rho \in \mathrm{u}_{\mathrm{i}}\right)= & \frac{\partial}{\partial \mathrm{x}_{\mathrm{j}}}\left|\left(\mu+\frac{\mu_{\mathrm{t}}}{\sigma_{\epsilon}}\right) \frac{\partial \epsilon}{\partial \mathrm{x}_{\mathrm{j}}}\right|+ \\
& \mathrm{C}_{1 \in \frac{\varepsilon}{\mathrm{k}}}\left(\mathrm{p}_{\mathrm{k}}+\mathrm{C}_{3 \in} \mathrm{p}_{\mathrm{b}}\right)-\mathrm{C}_{2 \epsilon} \rho \frac{\epsilon^{2}}{\mathrm{k}}+\mathrm{S}_{\epsilon}
\end{aligned}
$$

Where:

$$
\begin{aligned}
& \mathrm{C}_{1 \varepsilon}=1.44 \\
& \mathrm{C}_{2 \varepsilon}=1.92 \\
& \mathrm{C}_{\mu}=0.09 \\
& \mathrm{~S}_{\mathrm{k}}=1.0 \\
& \mathrm{~S}_{\varepsilon}=1.3
\end{aligned}
$$

The amount of viscous drag force and pressure drag force $F_{d}$ can be written in equations as follows:

$$
F_{d}=\int \tau_{w} \sin \theta d S+\int \rho \cos \theta d S
$$

where, $C_{d}$ is drag coefficient which expressed as:

$$
C_{d}=\int \frac{\tau_{w}}{\frac{1}{2} \rho V_{\infty}^{2} S} \sin \theta d S+\frac{\int C \rho \cos \theta d S}{S}
$$

Where:

$\tau_{\mathrm{w}}=\mu(\mathrm{du} / \mathrm{dy})_{\mathrm{w}}$ is the wall shear stress evaluated from the velocity gradient at the wall

$\mathrm{C}_{\mathrm{p}}=\left(\mathrm{p}-\mathrm{p}_{\infty}\right) /\left(\rho \mathrm{V}_{\infty}^{2} / 2\right)$ is pressure coefficient evaluated from pressure distribution at the wall

Experimental setup: The tests of experimental model were carried out in a controlled low speed wind tunnel. The investigation used van model made of acrylic material with a 0.25 scale with the original Ahmed body model (Ahmed et al., 1984). The van model consisted of two test models, i.e., model without flow control and model with 
active flow control by suction. The suction was placed inside the body of the model at the region where the flow separation was predicted to cause a significant drag based on the computational results. The suction was done by using vacuum pump. The suction velocity was set at $1 \mathrm{~m} \mathrm{sec}^{-1}$. Both models were placed in a low speed wind tunnel test section with free stream air flow. The low speed wind tunnel had length $260 \mathrm{~cm}$ and feeder diameter $55 \mathrm{~cm}$.

The wind tunnels flow was driven by axial blower DC motor with $2800 \mathrm{rpm}$ of speed and $1.5 \mathrm{~kW}$ of power. The low speed wind tunnel had a diffuser to produce uniform flow at the test section.

The maximum air velocity that can be achieved in the test section is $70 \mathrm{~km} \mathrm{~h}^{-1}$ or $19.44 \mathrm{~m} \mathrm{sec}^{-1}$. The turbulence intensity and flow velocity in the test section of the wind tunnel was measured in advanced for ensuring a steady state flow condition using a hot wire anemometry system. The average turbulence intensity obtained on the test section at free-stream velocity $7.16 \mathrm{~m} \mathrm{sec}^{-1}$ was about $0.55 \%$ which was sufficient to consider that the test section had a steady flow condition at free stream velocity.

Parameters to be studied was the aerodynamic drag force which was measured by using a load cell as shown in Fig. 3. The aerodynamic drag force measurement scheme is shown in Fig. 4.
The load cells used in the experimental approach consisted of strain gauges and signal conditioning. Strain gauge type was foil strain gauge (SHOWA Measuring Instruments Co., Ltd./N11-FA-5-350-11) and had gauge length $5 \mathrm{~mm}$ and thermal output of $\pm 2 \mu \varepsilon /{ }^{\circ} \mathrm{C}$. To read the output voltage of the strain gauge a signal conditioning equipment (Excellent Scale/XK3190-A12) was used.

This signal conditioning system has sample rate of 10 time $\mathrm{sec}^{-1}$ and load cell sensitivity of $1.5-3 \mathrm{mV} \mathrm{V}^{-1}$. Prior to the main experiments, the load cell was calibrated using a digital balance and a prelimary measurement was conducted to determine the statistical uncertainty of force measurement.

It was predicted that the uncertainty was about $\pm 2 \%$. Dimensionless coefficient called drag coefficient and related to drag force acting on the bluff body is then defined as follow:

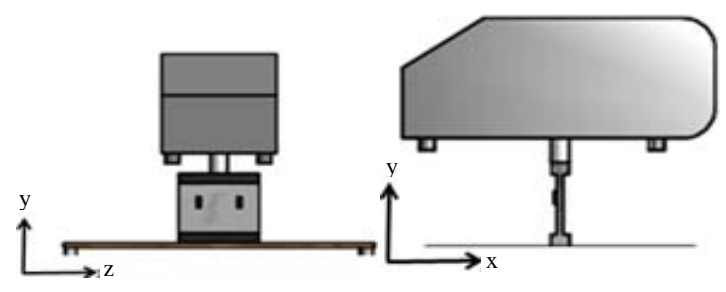

Fig. 3: Sketch of model test placement to the load cell

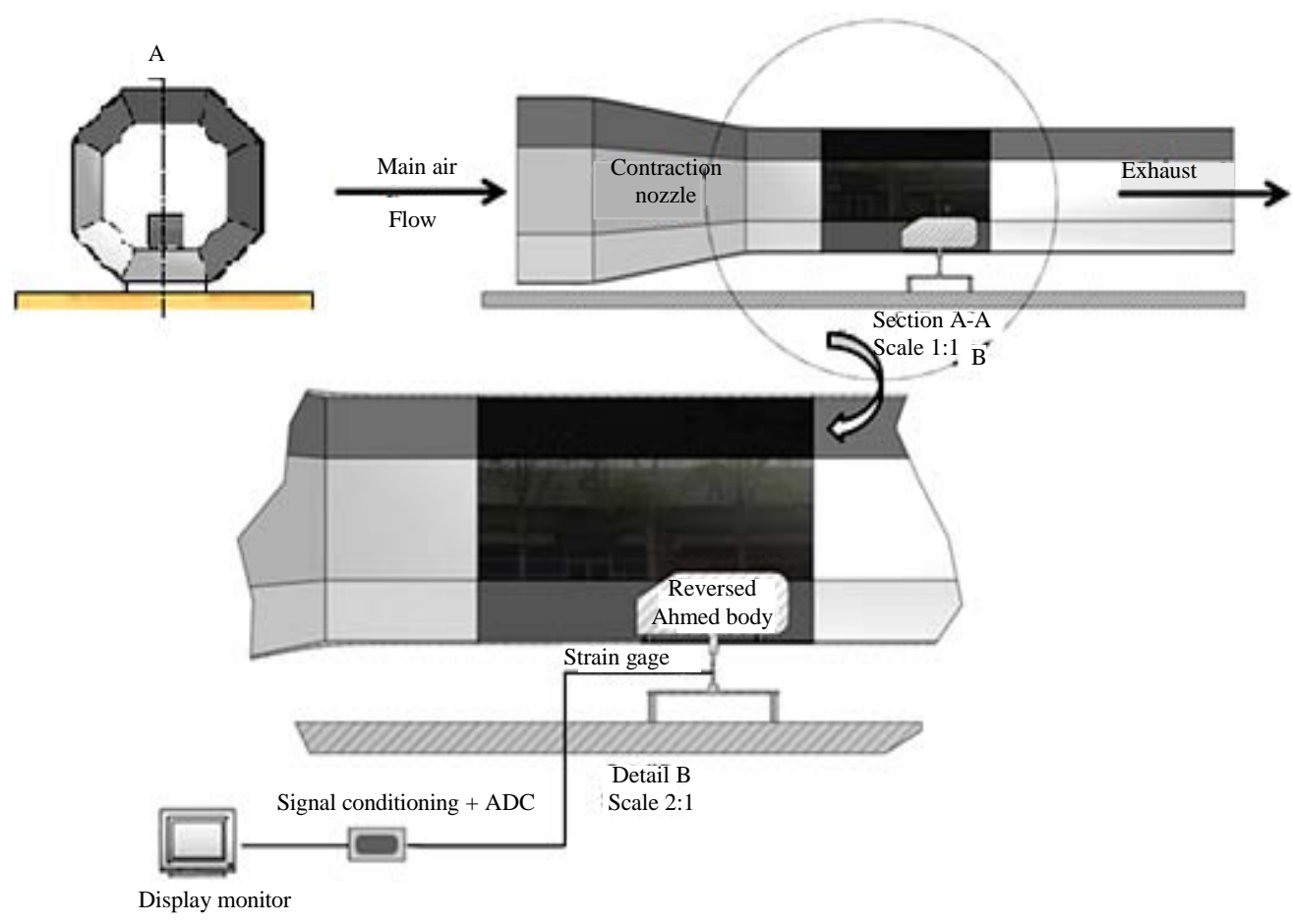

Fig. 4: Experimental set up for aerodynamic drag force measurement 


$$
C_{d}=\int \frac{F_{d}}{\frac{1}{2} \rho V_{\infty}^{2} S}
$$

Where:

$\rho=$ Air density

$\mathrm{V}_{\infty}=$ Free stream velocity

$\mathrm{S}=$ Cross section area

$F_{d}=$ Total drag force which works on vehicles model measured by a load cell

\section{RESULTS AND DISCUSSION}

Flow field: Some selected results from computational as well as experimental works are described as Fig. 5a and b compares computational result of flow structure alteration between the case of no flow control and when using flow control by suction at $U_{\mathrm{sc}}=1 \mathrm{~m} \mathrm{sec}^{-1}$ at the rear part of the van model with the upstream velocity,
$\mathrm{U}_{0}=11.1 \mathrm{~m} \mathrm{sec}^{-1}$. Figure 5 shows the path line colored by velocity field. Figure 5a shows the formation of the swirling structure (vortex) behind the rear part of the body near the side wall and the wheels which interact to each other and contribute to the complexity of the near wake flow region.

Flow separation occurs because the fluid flow can not follows the shape of the object surface. Wake structure, other than caused by flow separation is also influenced by the presence of longitudinal vortices that appear at the edges of the side, rear side of the test model. Longitudinal vortex is formed due to the flow velocity difference between the wake and the side area of the test model.

According to Onorato et al. (1984) other than those caused by the separated flow and pressure loss, the formation of aerodynamic drag on vehicles also stems from the effect of longitudinal vortex interaction.
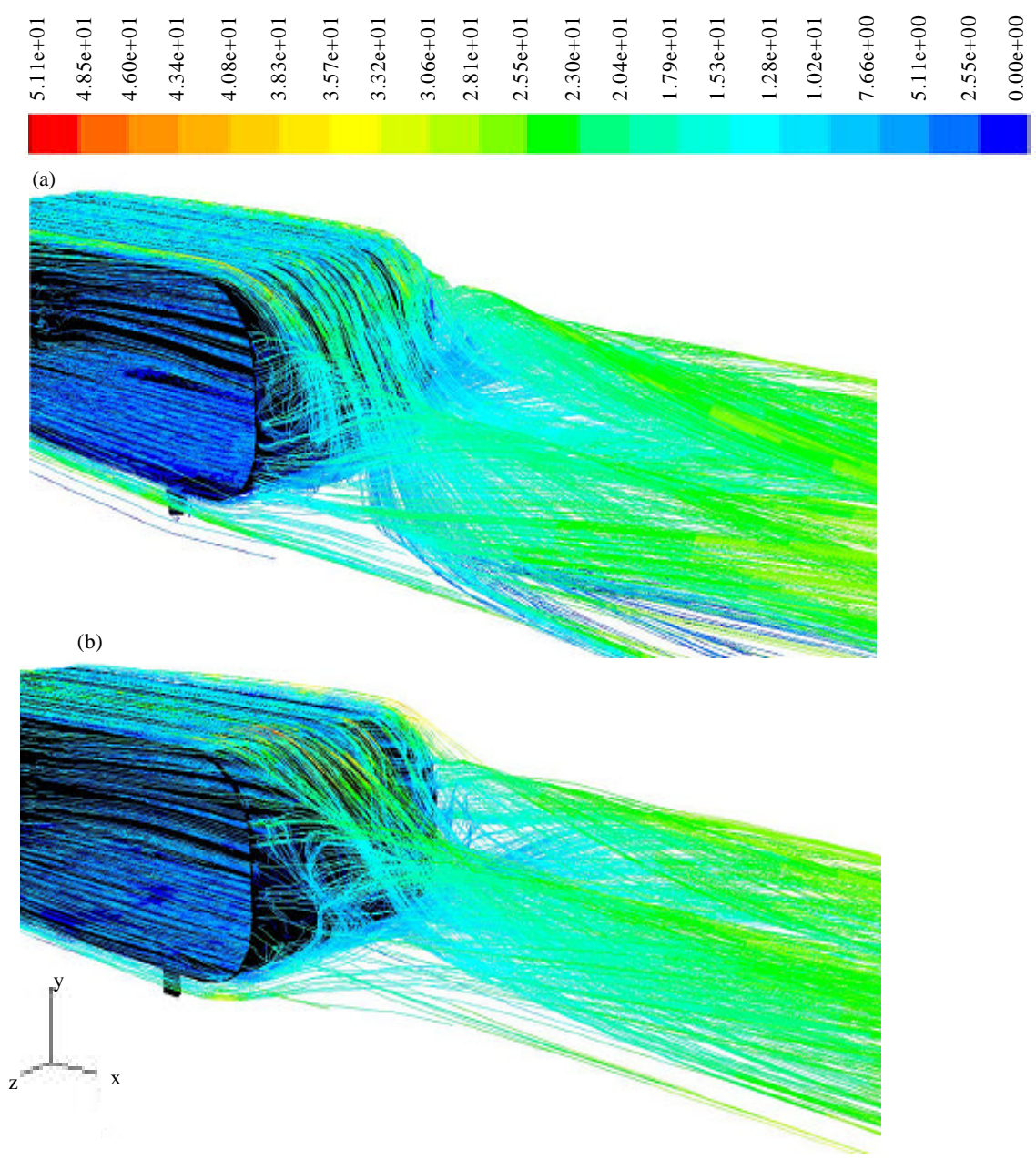

Fig. 5: Pathline of the flow field at the rear part of the van model with the upstream velocity, $U_{0}=11.1 \mathrm{~m} \mathrm{sec}^{-1}$; a) without flow control; b) with flow control by suction, $\mathrm{U}_{\mathrm{sc}}=1 \mathrm{~m} \mathrm{sec}^{-1}$ 


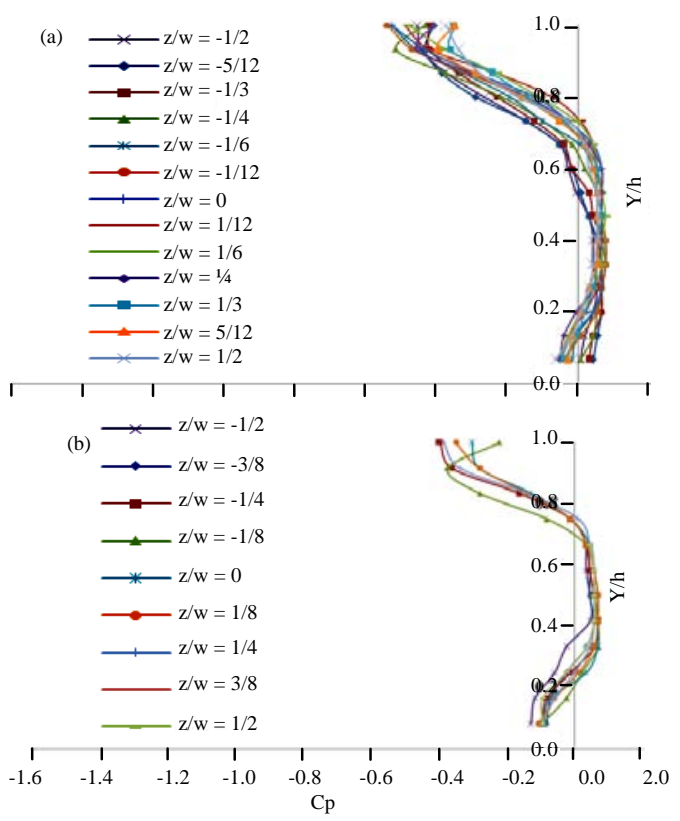

Fig. 6: Coefficient of pressure distribution at the rear of the of van model with the upstream velocity, $\mathrm{U}_{0}=11.1 \mathrm{~m} \mathrm{sec}^{-1}$; a) without flow control; b) with flow control by suction, $\mathrm{U}_{\mathrm{sc}}=1 \mathrm{~m} \mathrm{sec}^{-1}$

Therefore, the flow control is placed on the back side of the flow near the longitudinal side edge where the vortex is formed. The aim of installing this flow control is to reduce the vortex structure formation to reduce the wake area and to reduce the total pressure loss in the wake. Meanwhile, Fig. 5b shows the effect of placement of the flow control by suction with velocity is $1 \mathrm{~m} \mathrm{sec}^{-1}$ in the rear part of the van model with the upstream velocity at $11.1 \mathrm{~m} \mathrm{sec}^{-1}$. The figure indicates that flow suction gives the effect of reducing the wake and the vortex formation. Figure $6 \mathrm{a}$ and $\mathrm{b}$ shows computational result of pressure coefficient distribution comparison between the condition without flow control and the condition when flow control by suction is used with $U_{s c}=1 \mathrm{~m} \mathrm{sec}^{-1}$ at the rear part of the van model with the upstream velocity, $\mathrm{U}_{0}=11.1 \mathrm{~m} \mathrm{sec}^{-1}$.

From Fig. 6a, it can be shown that minimum value of pressure coefficient is -0.5384 at $y / h=1$ and $z / w=-1 / 12$ in the rear of the van model. Meanwhile, Fig. $6 \mathrm{~b}$ shows that by introducing suction with velocity $1 \mathrm{~m} \mathrm{sec}^{-1}$, the location of minimum value of pressure coefficient shifted significantly to $y / h=1 ; z / w=-1 / 4$ in the rear side of the body.

The minimum value of pressure coefficient is about -0.3957 . Therefore, the increase of minimum value of pressure coefficient about $26.5 \%$ has been obtained at suction velocity of $1 \mathrm{~m} \mathrm{sec}$. It indicates that the

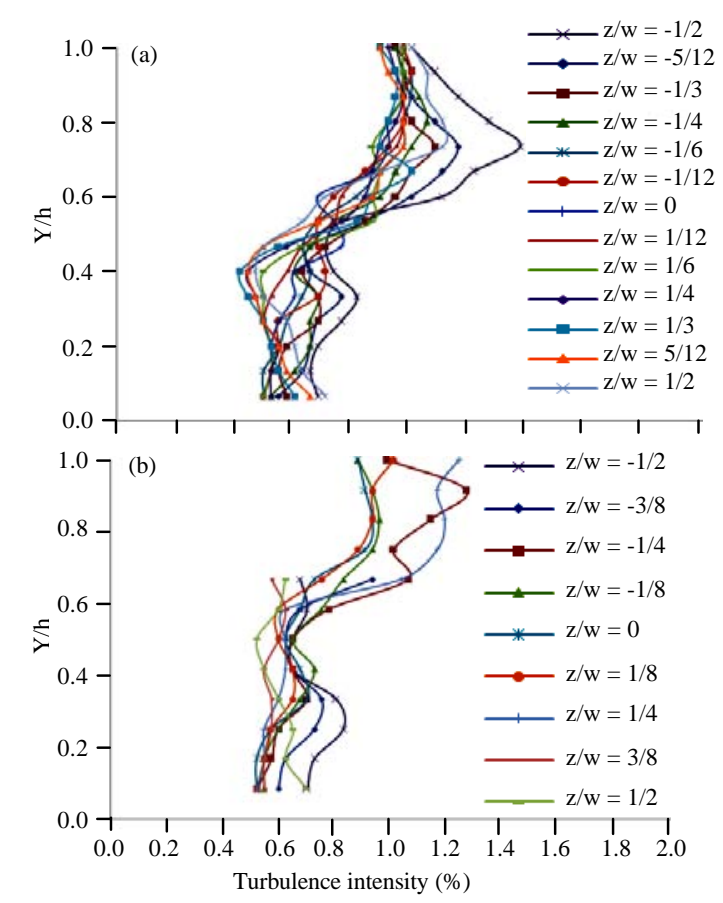

Fig. 7: Turbulence intensity at the rear of the of the van model with the upstream velocity, $\mathrm{U}_{0}=11.1 \mathrm{~m}$ $\mathrm{sec}^{-1}$; a) without flow control; b) with flow control by suction, $\mathrm{U}_{\mathrm{sc}}=1 \mathrm{~m} \mathrm{sec}^{-1}$

application of suction in the van model is able to reduce the total pressure loss and increase the static pressure at the surface of the object or model. This result supports findings which have been indicated by other studies (Roumeas et al., 2009; Gad-El-Hak, 1996; Fares, 2006).

Turbulence intensity: Figure 7 shows computational result of turbulence intensity comparison between the condition without flow control and the condition when flow control by suction is used with $\mathrm{U}_{\mathrm{sc}}=1 \mathrm{~m} \mathrm{sec}^{-1}$ at the rear part of the van model with the upstream velocity, $\mathrm{U}_{0}=11.1 \mathrm{~m} \mathrm{sec}^{-1}$. Figure $7 \mathrm{a}$ shows the characteristics of turbulence intensity without flow control in the rear part of the van model with the upstream velocity at $11.1 \mathrm{~m}$ $\mathrm{sec}^{-1}$. It can be seen that the maximum value of turbulence intensity is about $1.38 \%$. Furthermore, Fig. $7 \mathrm{~b}$ shows the effect of suction velocity in the rear part of the van model to the turbulence intensity distribution with the upstream velocity at $11.1 \mathrm{~m} \mathrm{sec}^{-1}$. The maximum turbulence intensity under suction velocity of $1 \mathrm{~m} \mathrm{sec}^{-1}$ is about $1.27 \%$. These results indicate that there is a decrease in the turbulence intensity by the use of suction mechanism in the rear part of the body. The decrease of turbulence intensity about $8 \%$ has been obtained at suction velocity of $1 \mathrm{~m} \mathrm{sec}^{-1}$. 
Table 2: Drag coefficient (Cd) by computational approach

\begin{tabular}{lc}
\hline Description & Drag Coefficient $(\mathrm{Cd})$ \\
\hline Without flow control & 1.838 \\
With suction $\left(\mathrm{U}_{\mathrm{sc}}=1 \mathrm{~m} \mathrm{sec}^{-1}\right)$ & 1.598 \\
\hline
\end{tabular}

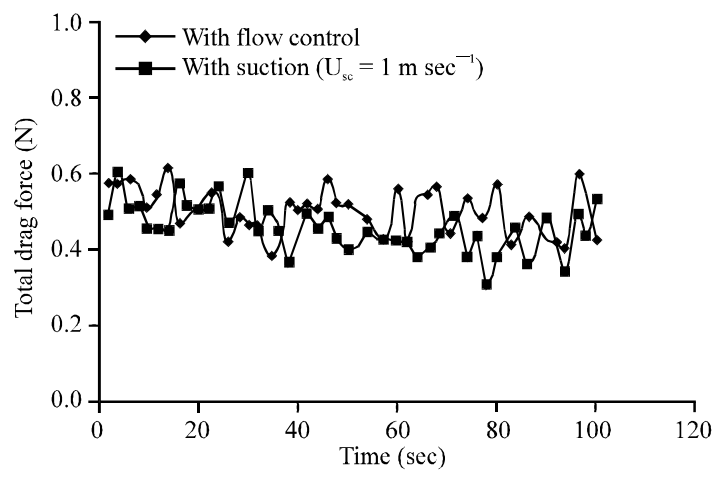

Fig. 8: Fluctuated drag force data at upstream velocity Uo $=11.1 \mathrm{~m} \mathrm{sec}^{-1}$ taken by experimental test; a) without flow control; b) with flow control by suction, $\mathrm{U}_{\mathrm{sc}}=1 \mathrm{~m} \mathrm{sec}^{-1}$

Computed aerodynamic drag: Result of drag coefficient obtained by using a computational approach is shown in Table 2. Table 2 shows that the computational approach, the drag coefficient of about 1.838 have been obtained without flow control. By introducing flow control by suction with velocity $1 \mathrm{~m} \mathrm{sec}^{-1}$ on the back of the van model, the obtained drag coefficient is about 1.598 . Thus, a drag reduction about $24 \%$ have been obtained with the presence of suction with velocity is $1 \mathrm{~m} \mathrm{sec}^{-1}$.

Measured drag force: Experimental work was carried out to validate the results of numerical computation for the aerodynamic drag. It was measured by using a load cell. The number of drag force data was 50 for each run. It was taken at upstream velocity $11.1 \mathrm{~m} \mathrm{sec}^{-1}$ for both test models, i.e., without flow control and with active flow control by suction at velocity $1 \mathrm{~m} \mathrm{sec}^{-1}$. Data retrieval time interval was $100 \mathrm{sec}$ and a typical fluctuated data obtained is shown in Fig. 8. Experimentally, the influences of suction is analyzed according to the aerodynamic forces applied to the geometry with and without control. The results are presented through aerodynamic drag reduction with respect to the reference configuration (without control). The mean drag coefficients, obtained at velocity of suction is showed in Table 3 .

From Table 3 , it appears that with the experimental approach, the obtained drag coefficient is about 1.702 without flow control. The placement of the flow control by suction with velocity $1 \mathrm{~m} \mathrm{sec}^{-1}$ in the rear part of the van model with the upstream velocity at $11.1 \mathrm{~m} \mathrm{sec}^{-1}$ reduces
Table 3: Drag coefficient (Cd), by experimental measurement

\begin{tabular}{lc}
\hline Description & Drag Coefficient (Cd) \\
Without flow control & 1.702
\end{tabular}

With suction $\left(\mathrm{U}_{s c}=1 \mathrm{~m} \mathrm{sec}^{-1}\right)$

Table 4: Comparison drag coefficient (Cd)

\begin{tabular}{|c|c|c|c|}
\hline Description & $\begin{array}{l}\text { Without } \\
\text { flow control }\end{array}$ & $\begin{array}{c}\text { With suction } \\
\left(\mathrm{U}_{\mathrm{sc}}=1 \mathrm{~m} \mathrm{sec}^{-1}\right)\end{array}$ & Cd reduction $(\%)$ \\
\hline Computational & 1.838 & 1.598 & 24.0 \\
\hline Experiment & 1.702 & 1.554 & 14.8 \\
\hline Difference & $7.400 \%$ & $2.800 \%$ & 9.2 \\
\hline
\end{tabular}

the drag coefficient to about 1.554. Thus, the drag reduction about $14.8 \%$ have been obtained. Futhermore, the comparison of drag coefficient obtained by computational and experimental approach can be shown in Table 4. Table 4 shows that the difference of drag coefficient between experiment and computational approach is about $7.4 \%$ for the case of without flow control.

Meanwhile, for the case with suction flow control at suction velocity $1 \mathrm{~m} \mathrm{sec}^{-1}$ the difference is about $2.8 \%$. Although, drag reduction obtained by computational and experimental approaches has a difference for $9.2 \%$ but both approaches produce the same tendency to the characteristic of suction effect for supporting the drag reduction.

\section{CONCLUSION}

Active technique by suction has been applied to control the flow structure over a van model. Introducing a suction in the rear part of the van model give the effect of reducing the wake and the vortex formation. The increase of minimum value of pressure coefficient close to $26.5 \%$ and the decrease of turbulence intensity for about $8 \%$ have been obtained. These flow field alterations due to the suction control support an aerodynamics drag reduction to the van model as verified by computational approach (up to $24 \%$ ) as well as by experimental approach (up to $14.8 \%$ ).

\section{ACKNOWLEDGEMENT}

The researchers would like to thank the Ministry of Research and Technology, Republic of Indonesia for funding this research through Research IncentiveFundamental Research Grant 2011, Contract No. RD-2011 0863.

\section{REFERENCES}

Ahmed, S.R., G. Ramm and G. Falting, 1984. Some salient features of the time averaged ground vehicle wake. SAE paper 840300 . 
Bruneau, C.H., E. Creuse, D. Depeyras, P. Gillieron and I. Mortazavi, 2010. Coupling active and passive techniques to control the flow past the square back Ahmed body. Comput. Fluids, 39: $1875-1892$.

Fares, E., 2006. Unsteady flow simulation of the Ahmed reference body using a lattice Boltzmann approach. Comput. Fluids, 35: 940-950.

Gad-El-Hak, M., 1996. Modern developments in flow control. Appeared Applied Mech. Rev., 49: 365-379.

Gillieron, P. and A. Spohn, 2002. Flow separations generated by a simplied geometry of an automotive vehicle. IUTAM Symp., Unsteady Separated Flows.

Gillieron, P. and F. Chometon, 1999. Modelling of stationary three-dimensional detached airflows around an Ahmed reference body. ESAIM Proc., 7: 173-182.

Harinaldi, Budiarso, R. Tarakka and S.P. Simanungkalit, 2011. Computational analysis of active flow control to reduce aerodynamics drag on a van model. Int. J. Mech. Mechatron. Eng., 11: 24-30.

International Energy Agency, 2007. World Energy Outlook 2007: China and India Insights. 1st Edn., International Energy Agency Publications, Paris, France, ISBN-13: 978-9264027305.
Kassim, Z.M. and A. Filippone, 2010. Fuel savings on a heavy vehicle via aerodynamic drag reduction. Transp. Res. Part D, 15: 275-284.

Kourta, A. and P. Gillieron, 2009. Impact of the automotive aerodynamic control on the economics issues. $\mathrm{J}$. Applied Fluid Mech., 2: 69-75.

Onorato, M., A.F. Costelli and A. Garonne, 1984. Drag measurement through wake analysis. Proceedings of the SAE, SP-569, International Congress and Exposition, February, 1984, Detroit, MI, pp: 85-93.

Rose, M.J., 1981. Commercial vehicle fuel economy: The correlation between aerodynamic drag and fuel consumption of a typical truck. J. Wind Eng. Ind. Aerodyn., 9: 89-100.

Roumeas, M., P. Gillieron and A. Kourta, 2009. Analysis and control of the near-wake flow over a square-back geometry. Comput. Fluids, 38: 60-70.

Uruba, V. and O. Hladik, 2009. On the Ahmed body wake, colloquium fluid dynamics. Institute of Thermomechanics AS CR, v.v.i., Prague.

Watkins, S. and V. Gioacchino, 2008. The effect of vehicle spacing on the aerodynamics of a representative car shape. J. Wind Eng. Ind. Aerodyn., 96: 1232-1239. 